\title{
Strong convergence theorems for solutions of fixed point and variational inequality problems
}

\author{
Lanxiang $\mathrm{Yu}^{1 *}$ and Jianmin Song ${ }^{2}$
}

\footnotetext{
"Correspondence: hdyulx@yeah.net 'school of Mathematics and Physics, North China Electric Power University, Baoding, 071003, China Full list of author information is available at the end of the article
}

\begin{abstract}
The purpose of this paper is to investigate viscosity approximation methods for finding a common element in the set of fixed points of a strict pseudocontraction and in the set of solutions of a generalized variational inequality in the framework of Banach spaces.
\end{abstract}

Keywords: sunny nonexpansive retraction; inverse-strongly accretive mapping; nonexpansive mapping; variational inequality

\section{Introduction}

Let $C$ be a nonempty, closed and convex subset of a real Hilbert space $H$, and let $P_{C}$ be the metric projection of $H$ onto $C$. Recall that a mapping $A: C \rightarrow H$ is said to be monotone iff

$$
\langle A x-A y, x-y\rangle \geq 0 \quad \forall x, y \in C .
$$

Recall that a mapping $A: C \rightarrow H$ is said to be inverse-strongly monotone iff there exists a positive real number $\alpha>0$ such that

$$
\langle A x-A y, x-y\rangle \geq \alpha\|A x-A y\|^{2} \quad \forall x, y \in C .
$$

For such a case, $A$ is said to be $\alpha$-inverse-strongly monotone.

Recall that the classical variational inequality problem, denoted by $\operatorname{VI}(C, A)$, is to find $u \in C$ such that

$$
\langle A u, v-u\rangle \geq 0 \quad \forall v \in C .
$$

It is clear that variational inequality problem (1.1) is equivalent to a fixed point problem. $u$ is a solution of the above inequality iff it is a fixed point of the mapping $P_{C}(I-r A)$, where $I$ is the identity and $r$ is some positive real number.

Variational inequality problems have emerged as an effective and powerful tool for studying a wide class of problems which arise in economics, finance, image reconstruction, ecology, transportation, and network. Recently, many authors studied the solutions of inequality (1.1) based on iterative methods; see [1-17] and the references therein.

○2014 Yu and Song; licensee Springer. This is an Open Access article distributed under the terms of the Creative Commons Attribution License (http://creativecommons.org/licenses/by/2.0), which permits unrestricted use, distribution, and reproduction in any medium, provided the original work is properly cited. 
Let $S: C \rightarrow C$ be a mapping. In this paper, we denote by $F(S)$ the set of fixed points of the mapping $S$.

Recall that $S$ is said to be nonexpansive iff

$$
\|S x-S y\| \leq\|x-y\| \quad \forall x, y \in C .
$$

Recall that $S$ is said to be a strict pseudocontraction iff there exits a positive constant $\lambda$ such that

$$
\|S x-S y\|^{2} \leq\|x-y\|^{2}+\lambda\|(I-S) x-(I-S) y\|^{2} \quad \forall x, y \in C .
$$

It is clear that the class of strict pseudocontractions includes the class of nonexpansive mappings as a special case.

Recently, many authors have investigated the problems of finding a common element in the set of solution of variational inequalities for an inverse-strongly monotone mapping and in the set of fixed points of nonexpansive mappings or strict pseudocontractions; see [18-25] and the references therein. However, most of the results are in the framework of Hilbert spaces. In this paper, we investigate a common element problem in the framework of Banach spaces. A strong convergence theorem for common solutions to fixed point problems of strict pseudocontractions and solution problems of variational inequality (1.1) is established in uniformly convex and 2-uniformly smooth Banach spaces. The results presented in this paper improve and extend the corresponding results announced by Iiduka and Takahashi [5] and Hao [26].

\section{Preliminaries}

Let $C$ be a nonempty closed and convex subset of a Banach space $E$. Let $E^{*}$ be the dual space of $E$, and let $\langle\cdot, \cdot\rangle$ denote the pairing between $E$ and $E^{*}$. For $q>1$, the generalized duality mapping $J_{q}: E \rightarrow 2^{E^{*}}$ is defined by

$$
J_{q}(x)=\left\{f \in E^{*}:\langle x, f\rangle=\|x\|^{q},\|f\|=\|x\|^{q-1}\right\}
$$

for all $x \in E$. In particular, $J=J_{2}$ is called the normalized duality mapping. It is known that $J_{q}(x)=\|x\|^{q-2} J(x)$ for all $x \in E$. If $E$ is a Hilbert space, then $J=I$, the identity mapping. The normalized duality mapping $J$ has the following properties:

(1) if $E$ is smooth, then $J$ is single-valued;

(2) if $E$ is strictly convex, then it is one-to-one and $\left\langle x-y, x^{*}-y^{*}\right\rangle>0$ holds for all $\left(x, x^{*}\right),\left(y, y^{*}\right) \in J$ with $x \neq y$;

(3) if $E$ is reflexive, then $J$ is surjective;

(4) if $E$ is uniformly smooth, then $J$ is uniformly norm-to-norm continuous on each bounded subset of $E$.

Let $U=\{x \in X:\|x\|=1\}$. A Banach space $E$ is said to be uniformly convex if, for any $\epsilon \in(0,2]$, there exists $\delta>0$ such that, for any $x, y \in U$,

$$
\|x-y\| \geq \epsilon \quad \text { implies } \quad\left\|\frac{x+y}{2}\right\| \leq 1-\delta .
$$

It is known that a uniformly convex Banach space is reflexive and strictly convex. Hilbert spaces are 2-uniformly convex, while $L^{p}$ is $\max \{p, 2\}$-uniformly convex for every $p>1$. 
A Banach space $E$ is said to be smooth if the limit

$$
\lim _{t \rightarrow 0} \frac{\|x+t y\|-\|x\|}{t}
$$

exists for all $x, y \in U$. It is also said to be uniformly smooth if the limit (2.1) is attained uniformly for $x, y \in U$. The norm of $E$ is said to be Fréchet differentiable if, for any $x \in$ $U$, the limit (2.1) is attained uniformly for all $y \in U$. The modulus of smoothness of $E$ is defined by

$$
\rho(\tau)=\sup \left\{\frac{1}{2}(\|x+y\|+\|x-y\|)-1: x, y \in X,\|x\|=1,\|y\|=\tau\right\},
$$

where $\rho:[0, \infty) \rightarrow[0, \infty)$ is a function. It is known that $E$ is uniformly smooth if and only if $\lim _{\tau \rightarrow 0} \frac{\rho(\tau)}{\tau}=0$. Let $q$ be a fixed real number with $1<q \leq 2$. A Banach space $E$ is said to be $q$-uniformly smooth if there exists a constant $c>0$ such that $\rho(\tau) \leq c \tau^{q}$ for all $\tau>0$.

We remark that all Hilbert spaces, $L_{p}$ (or $\left.l_{p}\right)$ spaces $(p \geq 2)$ and the Sobolev spaces $W_{m}^{p}$ $(p \geq 2)$ are 2 -uniformly smooth, while $L_{p}$ (or $\left.l_{p}\right)$ and $W_{m}^{p}$ spaces $(1<p \leq 2)$ are $p$-uniformly smooth. Typical examples of both uniformly convex and uniformly smooth Banach spaces are $L^{p}$, where $p>1$. More precisely, $L^{p}$ is $\min \{p, 2\}$-uniformly smooth for every $p>1$.

Recall that a mapping $S$ is said to be $\lambda$-strictly pseudocontractive iff there exist a constant $\lambda \in(0,1)$ and $j(x-y) \in J(x-y)$ such that

$$
\langle S x-S y, j(x-y)\rangle \leq\|x-y\|^{2}-\lambda\|(I-S) x-(I-S) y\|^{2} \quad \forall x, y \in C .
$$

It is clear that (2.2) is equivalent to the following:

$$
\langle(I-S) x-(I-S) y, j(x-y)\rangle \geq \lambda\|(I-S) x-(I-S) y\|^{2} \quad \forall x, y \in C .
$$

Next, we assume that $E$ is a smooth Banach space. Let $C$ be a nonempty closed convex subset of $E$. Recall that an operator $A$ of $C$ into $E$ is said to be accretive iff

$$
\langle A x-A y, J(x-y)| \geq 0 \quad \forall x, y \in C .
$$

An accretive operator $A$ is said to be $m$-accretive if the range of $I+r A$ is $E$ for all $r>0$. In a real Hilbert space, an operator $A$ is $m$-accretive if and only if $A$ is maximal monotone.

Recall that an operator $A$ of $C$ into $E$ is said to be $\alpha$-inverse strongly accretive iff there exits a real constant $\alpha>0$ such that

$$
\langle A x-A y, J(x-y)| \geq \alpha\|A x-A y\|^{2} \quad \forall x, y \in C .
$$

Evidently, the definition of an inverse-strongly accretive operator is based on that of an inverse-strongly monotone operator.

Let $D$ be a subset of $C$ and $Q$ be a mapping of $C$ into $D$. Then $Q$ is said to be sunny if

$$
Q(Q x+t(x-Q x))=Q x,
$$


whenever $Q x+t(x-Q x) \in C$ for $x \in C$ and $t \geq 0$. A mapping $Q$ of $C$ into itself is called a retraction if $Q^{2}=Q$. If a mapping $Q$ of $C$ into itself is a retraction, then $Q z=z$ for all $z \in R(Q)$, where $R(Q)$ is the range of $Q$. A subset $D$ of $C$ is called a sunny nonexpansive retract of $C$ if there exists a sunny nonexpansive retraction from $C$ onto $D$.

The following result describes a characterization of sunny nonexpansive retractions on a smooth Banach space.

Proposition 2.1 [27] Let E be a smooth Banach space, and let $C$ be a nonempty subset of E. Let $Q: E \rightarrow C$ be a retraction, and let J be the normalized duality mapping on $E$. Then the following are equivalent:

(1) $Q_{C}$ is sunny and nonexpansive;

(2) $\left\|Q_{C} x-Q_{C} y\right\|^{2} \leq\left\langle x-y, J\left(Q_{C} x-Q_{C} y\right)\right\rangle \forall x, y \in E$;

(3) $\left\langle x-Q_{C} x, J\left(y-Q_{C} x\right)\right\rangle \leq 0 \forall x \in E, y \in C$.

Proposition 2.2 [28] Let C be a nonempty closed convex subset of a uniformly convex and uniformly smooth Banach space $E$, and let $T$ be a nonexpansive mapping of $C$ into itself with $F(T) \neq \emptyset$. Then the set $F(T)$ is a sunny nonexpansive retract of $C$.

Recently, Aoyama et al. [29] considered the following generalized variational inequality problem.

Let $C$ be a nonempty closed convex subset of $E$, and let $A$ be an accretive operator of $C$ into $E$. Find a point $u \in C$ such that

$$
\langle A u, J(v-u)\rangle \geq 0 \quad \forall v \in C .
$$

Next, we use $\operatorname{BVI}(C, A)$ to denote the set of solutions of variational inequality problem (2.4).

Aoyama et al. [29] proved that variational inequality (2.4) is equivalent to a fixed point problem. The element $u \in C$ is a solution of variational inequality (2.4) iff $u \in C$ is a fixed point of the mapping $Q_{C}(I-r A)$, where $r>0$ is a constant and $Q_{C}$ is a sunny nonexpansive retraction from $E$ onto $C$.

The following lemmas also play an important role in this paper.

Lemma 2.3 [30] Assume that $\left\{\alpha_{n}\right\}$ is a sequence of nonnegative real numbers such that

$$
\alpha_{n+1} \leq\left(1-\gamma_{n}\right) \alpha_{n}+\delta_{n}+e_{n}
$$

where $\left\{\gamma_{n}\right\}$ is a sequence in $(0,1),\left\{e_{n}\right\}$ and $\left\{\delta_{n}\right\}$ are sequences such that

(1) $\sum_{n=1}^{\infty} \gamma_{n}=\infty$;

(2) $\sum_{n=1}^{\infty} e_{n}<\infty$;

(3) $\lim \sup _{n \rightarrow \infty} \delta_{n} / \gamma_{n} \leq 0$ or $\sum_{n=1}^{\infty}\left|\delta_{n}\right|<\infty$.

Then $\lim _{n \rightarrow \infty} \alpha_{n}=0$.

Lemma 2.4 [31] Let E be a real 2-uniformly smooth Banach space with the best smooth constant $K$. Then the following inequality holds:

$$
\|x+y\|^{2} \leq\|x\|^{2}+2\langle y, J x\rangle+2\|K y\|^{2} \quad \forall x, y \in E .
$$


Lemma 2.5 [29] Let C be a nonempty closed convex subset of a smooth Banach space E. Let $Q_{C}$ be a sunny nonexpansive retraction from $E$ onto $C$, and let $A$ be an accretive operator of $C$ into $E$. Then, for all $\lambda>0$,

$$
\operatorname{BVI}(C, A)=F\left(Q_{C}(I-\lambda A)\right) .
$$

Lemma 2.6 [32] Let $C$ be a closed convex subset of a real strictly convex Banach space $E$ and $S_{i}: C \rightarrow C(i=1,2)$ be two nonexpansive mappings such that $F=F\left(S_{1}\right) \cap F\left(S_{2}\right) \neq \emptyset$. Define $S x=\delta S_{1} x+(1-\delta) S_{2} x$, where $\delta \in(0,1)$. Then $S: C \rightarrow C$ is a nonexpansive mapping with $F(S)=F \neq \emptyset$.

Lemma 2.7 [33] Let $C$ be a nonempty subset of a real 2-uniformly smooth Banach space $E$, and let $T: C \rightarrow C$ be a $\kappa$-strict pseudocontraction. For $\alpha \in(0,1)$, we define $T_{\alpha} x=(1-$ $\alpha) x+\alpha$ Tx for every $x \in C$. Then, as $\alpha \in\left(0, \frac{\kappa}{K^{2}}\right], T_{\alpha}$ is nonexpansive such that $F\left(T_{\alpha}\right)=F(T)$.

Lemma 2.8 [34] Let E be a real uniformly smooth Banach space, and let $C$ be a nonempty closed convex subset of E. Let $T: C \rightarrow C$ be a nonexpansive mapping with a fixed point, and let $f: C \rightarrow C$ be a contraction. For each $t \in(0,1)$, let $z_{t}$ be the unique solution of the equation $x=t f(x)+(1-t) T x$. Then $\left\{z_{t}\right\}$ converges to a fixed point of $T$ as $t \rightarrow 0$ and $Q(f)=s-\lim _{t \rightarrow 0} z_{t}$ defines the unique sunny nonexpansive retraction from $C$ onto $F(T)$.

\section{Main results}

Theorem 3.1 Let E be a uniformly convex and 2-uniformly smooth Banach space with the best smooth constant $K$, and let $C$ be a nonempty, closed and convex subset of $E$. Let $Q_{C}$ be a sunny nonexpansive retraction from $E$ onto $C$, and let $A: C \rightarrow E$ be an $\alpha$-inverse strongly accretive mapping. Let $S: C \rightarrow C$ be a $\lambda$-strict pseudocontraction with a fixed point. Assume that $F:=F(S) \cap \operatorname{BVI}(C, A) \neq \emptyset$. Let $\left\{\alpha_{n}\right\},\left\{\beta_{n}\right\}$ and $\left\{\gamma_{n}\right\}$ be real number sequences in $(0,1)$. Suppose that $x_{1}=x \in C$ and that $\left\{x_{n}\right\}$ is given by

$$
x_{n+1}=\alpha_{n} f\left(x_{n}\right)+\beta_{n}\left[\mu S_{t} x_{n}+(1-\mu) Q_{C}\left(x_{n}-\lambda A x_{n}\right)\right]+\gamma_{n} Q_{C} e_{n}, \quad n \geq 1,
$$

where $S_{t}=(1-t) x+t S x, t \in\left(0, \frac{\lambda}{K^{2}}\right], f: C \rightarrow C$ is a $\kappa$-contractive mapping, $\left\{e_{n}\right\}$ is a bounded computational error in $E, \lambda \in\left(0, \alpha / K^{2}\right]$ and $\mu \in(0,1)$. Assume that the following restrictions are satisfied:

(a) $\lim _{n \rightarrow \infty} \alpha_{n}=0, \sum_{n=1}^{\infty} \alpha_{n}=\infty$ and $\sum_{n=1}^{\infty}\left|\alpha_{n+1}-\alpha_{n}\right|<\infty$;

(b) $\sum_{n=1}^{\infty} \gamma_{n}<\infty$.

Then $\left\{x_{n}\right\}$ converges strongly to $x=Q_{F} f(x)$, where $Q_{F}$ is a sunny nonexpansive retraction from $C$ onto $F$.

Proof Fixing $x^{*} \in F$, we find that $x^{*}=Q_{C}\left(x^{*}-\lambda A x^{*}\right)$ and $S x^{*}=x^{*}$. It follows from Lemma 2.7 that $S_{t} x^{*}=x^{*}$. Put $y_{n}=Q_{C}\left(x_{n}-\lambda A x_{n}\right)$. In view of Lemma 2.4, we find that

$$
\begin{aligned}
\left\|y_{n}-x^{*}\right\|^{2} \leq & \left\|\left(x_{n}-x^{*}\right)-\lambda\left(A x_{n}-A x^{*}\right)\right\|^{2} \\
\leq & \left\|x_{n}-x^{*}\right\|^{2}-2 \lambda\left\langle A x_{n}-A x^{*}, J\left(x_{n}-x^{*}\right)\right\rangle \\
& +2 K^{2} \lambda^{2}\left\|A x_{n}-A x^{*}\right\|^{2}
\end{aligned}
$$




$$
\begin{aligned}
& \leq\left\|x_{n}-x^{*}\right\|^{2}-2 \lambda \alpha\left\|A x_{n}-A x^{*}\right\|^{2}+2 K^{2} \lambda^{2}\left\|A x_{n}-A x^{*}\right\|^{2} \\
& =\left\|x_{n}-x^{*}\right\|^{2}+2 \lambda\left(\lambda K^{2}-\alpha\right)\left\|A x_{n}-A x^{*}\right\|^{2}
\end{aligned}
$$

Since $\lambda \in\left(0, \alpha / K^{2}\right]$, we have that

$$
\left\|y_{n}-x^{*}\right\| \leq\left\|x_{n}-x^{*}\right\|
$$

This implies that $Q_{C}(I-\lambda A)$ is a nonexpansive mapping. Hence, we have

$$
\begin{aligned}
\left\|x_{n+1}-x^{*}\right\| & \left\|\alpha_{n} f\left(x_{n}\right)+\beta_{n}\left[\mu S x_{n}+(1-\mu) Q_{C}\left(x_{n}-\lambda A x_{n}\right)\right]+\gamma_{n} Q_{C} e_{n}-x^{*}\right\| \\
\leq & \alpha_{n}\left\|f\left(x_{n}\right)-x^{*}\right\|+\beta_{n}\left\|\mu S x_{n}+(1-\mu) Q_{C}\left(x_{n}-\lambda A x_{n}\right)-x^{*}\right\| \\
& +\gamma_{n}\left\|Q_{C} e_{n}-x^{*}\right\| \\
\leq & \alpha_{n}\left\|f\left(x_{n}\right)-x^{*}\right\|+\beta_{n} \mu\left\|x_{n}-x^{*}\right\|+\beta_{n}(1-\mu)\left\|x_{n}-x^{*}\right\| \\
& +\gamma_{n}\left\|Q_{C} e_{n}-x^{*}\right\| \\
\leq & \alpha_{n} \kappa\left\|x_{n}-x^{*}\right\|+\alpha_{n}\left\|f\left(x^{*}\right)-x^{*}\right\|+\beta_{n}\left\|x_{n}-x^{*}\right\| \\
& +\gamma_{n}\left\|e_{n}-x^{*}\right\| \\
\leq & \left(1-\alpha_{n}(1-\kappa)\right)\left\|x_{n}-x^{*}\right\|+\alpha_{n}\left\|f\left(x^{*}\right)-x^{*}\right\|+\gamma_{n}\left\|e_{n}-x^{*}\right\| \\
\leq & \max \left\{\left\|x_{n}-x^{*}\right\|, \frac{\left\|f\left(x^{*}\right)-x^{*}\right\|}{1-\kappa}\right\}+\gamma_{n}\left\|e_{n}-x^{*}\right\|,
\end{aligned}
$$

which implies that the sequence $\left\{x_{n}\right\}$ is bounded, so is $\left\{y_{n}\right\}$. Define

$$
t_{n}=\mu S_{t} x_{n}+(1-\mu) Q_{C}\left(x_{n}-\lambda A x_{n}\right)
$$

It follows that

$$
\begin{aligned}
& \left\|t_{n}-t_{n-1}\right\| \\
& \quad=\left\|\mu S_{t} x_{n}+(1-\mu) Q_{C}(I-\lambda A) x_{n}-\left[\mu S_{t} x_{n-1}+(1-\mu) Q_{C}(I-\lambda A) x_{n-1}\right]\right\| \\
& \quad \leq \mu\left\|S_{t} x_{n}-S_{t} x_{n-1}\right\|+(1-\mu)\left\|Q_{C}(I-\lambda A) x_{n}-Q_{C}(I-\lambda A) x_{n-1}\right\| \\
& \quad \leq \mu\left\|x_{n}-x_{n-1}\right\|+(1-\mu)\left\|x_{n}-x_{n-1}\right\| \\
& \quad=\left\|x_{n}-x_{n-1}\right\| .
\end{aligned}
$$

On the other hand, we have

$$
\begin{aligned}
& \left\|x_{n+1}-x_{n}\right\| \\
& \leq \alpha_{n}\left\|f\left(x_{n}\right)-f\left(x_{n-1}\right)\right\|+\left|\alpha_{n}-\alpha_{n-1}\right|\left\|f\left(x_{n-1}\right)\right\| \\
& \quad+\beta_{n}\left\|t_{n}-t_{n-1}\right\|+\left|\beta_{n}-\beta_{n-1}\right|\left\|t_{n-1}\right\|+\gamma_{n}\left\|Q_{C} e_{n}-Q_{C} e_{n-1}\right\| \\
& \quad+\left|\gamma_{n}-\gamma_{n-1}\right|\left\|Q_{C} e_{n}\right\| .
\end{aligned}
$$


Substituting (3.1) into (3.2), we see that

$$
\begin{aligned}
\| x_{n+1} & -x_{n} \| \\
\leq & \left(1-\alpha_{n}(1-\kappa)\right)\left\|x_{n}-x_{n-1}\right\|+\left|\alpha_{n}-\alpha_{n-1}\right|\left\|f\left(x_{n-1}\right)\right\| \\
& +\left|\beta_{n}-\beta_{n-1}\right|\left\|t_{n-1}\right\|+\gamma_{n}\left\|Q_{C} e_{n}-Q_{C} e_{n-1}\right\| \\
& +\left|\gamma_{n}-\gamma_{n-1}\right|\left\|Q_{C} e_{n}\right\| \\
\leq & \left(1-\alpha_{n}(1-\kappa)\right)\left\|x_{n}-x_{n-1}\right\|+\left|\alpha_{n}-\alpha_{n-1}\right|\left(\left\|f\left(x_{n-1}\right)\right\|+\left\|t_{n-1}\right\|\right) \\
& +\left|\gamma_{n}-\gamma_{n-1}\right|\left(\left\|t_{n-1}\right\|+\left\|Q_{C} e_{n}\right\|\right)+\gamma_{n}\left\|Q_{C} e_{n}-Q_{C} e_{n-1}\right\| .
\end{aligned}
$$

In view of Lemma 2.3, we find from the restrictions (a) and (b) that

$$
\lim _{n \rightarrow \infty}\left\|x_{n+1}-x_{n}\right\|=0
$$

Note that

$$
\begin{aligned}
\left\|x_{n}-t_{n}\right\| & \leq\left\|x_{n}-x_{n+1}\right\|+\left\|x_{n+1}-t_{n}\right\| \\
& \leq\left\|x_{n}-x_{n+1}\right\|+\alpha_{n}\left\|f\left(x_{n}\right)-t_{n}\right\|+\gamma_{n}\left\|Q_{C} e_{n}-t_{n}\right\| .
\end{aligned}
$$

Using (3.3), we find from the restrictions (a) and (b) that

$$
\lim _{n \rightarrow \infty}\left\|x_{n}-t_{n}\right\|=0
$$

Define a mapping $V$ by

$$
V x=\mu S_{t} x+(1-\mu) Q_{C}(I-\lambda A) x \quad \forall x \in C .
$$

Using Lemma 2.6, we see that the mapping $V$ is a nonexpansive mapping with

$$
F(V)=F\left(S_{t}\right) \cap F\left(Q_{C}(I-\lambda A)\right)=F\left(S_{t}\right) \cap \operatorname{BVI}(C, A)=F(S) \cap \operatorname{BVI}(C, A)=F .
$$

From (3.4), we see that

$$
\lim _{n \rightarrow \infty}\left\|x_{n}-V x_{n}\right\|=0
$$

Next, we show that

$$
\limsup _{n \rightarrow \infty}\left\langle f(x)-x, J\left(x_{n}-x\right)\right\rangle \leq 0
$$

where $x=Q_{F} f(x)$, and $Q_{F}$ is a sunny nonexpansive retraction from $C$ onto $F$, the strong limit of the sequence $z_{t}$ defined by

$$
z_{t}=t f\left(z_{t}\right)+(1-t) V z_{t}
$$


It follows that

$$
\left\|z_{t}-x_{n}\right\|=\left\|(1-t)\left(V z_{t}-x_{n}\right)+t\left(f\left(z_{t}\right)-x_{n}\right)\right\| .
$$

For any $t \in(0,1)$, we see that

$$
\begin{aligned}
\left\|z_{t}-x_{n}\right\|^{2} \leq & (1-t)^{2}\left\|V z_{t}-x_{n}\right\|^{2}+2 t\left\langle f\left(z_{t}\right)-x_{n}, j\left(z_{t}-x_{n}\right)\right\rangle \\
\leq & (1-t)^{2}\left(\left\|V z_{t}-V x_{n}\right\|^{2}+\left\|V x_{n}-x_{n}\right\|^{2}\right. \\
& \left.+2\left\|V z_{t}-V x_{n}\right\|\left\|V x_{n}-x_{n}\right\|\right)+2 t\left\langle f\left(z_{t}\right)-z_{t}, j\left(z_{t}-x_{n}\right)\right\rangle \\
& +2 t\left\langle z_{t}-x_{n}, j\left(z_{t}-x_{n}\right)\right\rangle \\
\leq & (1-t)^{2}\left\|z_{t}-x_{n}\right\|^{2}+\lambda_{n}(t)+2 t\left\langle f\left(z_{t}\right)-z_{t}, j\left(z_{t}-x_{n}\right)\right\rangle \\
& +2 t\left\|z_{t}-x_{n}\right\|^{2},
\end{aligned}
$$

where

$$
\lambda_{n}(t)=\left\|V x_{n}-x_{n}\right\|^{2}+2\left\|z_{t}-x_{n}\right\|\left\|V x_{n}-x_{n}\right\| .
$$

It follows from (3.7) that

$$
\left\langle z_{t}-f\left(z_{t}\right), j\left(z_{t}-x_{n}\right)\right\rangle \leq \frac{t}{2}\left\|z_{t}-x_{n}\right\|^{2}+\frac{1}{2 t} \lambda_{n}(t) .
$$

This implies that

$$
\limsup _{n \rightarrow \infty}\left\langle z_{t}-f\left(z_{t}\right), j\left(z_{t}-x_{n}\right)\right\rangle \leq \frac{t}{2}\left\|z_{t}-x_{n}\right\|^{2} .
$$

Since $E$ is 2-uniformly smooth, $j: E \rightarrow E^{*}$ is uniformly continuous on any bounded sets of $E$, which ensures that the $\limsup _{n \rightarrow \infty}$ and $\limsup _{t \rightarrow 0}$ are interchangeable, hence

$$
\limsup _{n \rightarrow \infty}\left\langle f(x)-x, j\left(x_{n}-x\right)\right\rangle \leq 0
$$

This shows that (3.6) holds.

Finally, we show that $x_{n} \rightarrow x$ as $n \rightarrow \infty$. Note that

$$
\begin{aligned}
\left\|x_{n+1}-x\right\|^{2} & \\
= & \alpha_{n}\left\langle f\left(x_{n}\right)-x, j\left(x_{n+1}-x\right)\right\rangle+\beta_{n}\left\langle t_{n}-x, j\left(x_{n+1}-x\right)\right\rangle \\
& +\gamma_{n}\left\langle Q_{C} e_{n}-x, j\left(x_{n+1}-x\right)\right\rangle \\
\leq & \alpha_{n}\left\langle f\left(x_{n}\right)-x, j\left(x_{n+1}-q\right)\right\rangle+\beta_{n}\left\|t_{n}-x\right\|\left\|x_{n+1}-x\right\| \\
& +\gamma_{n}\left\|Q_{C} e_{n}-x\right\|\left\|x_{n+1}-x\right\| \\
\leq & \alpha_{n} \kappa\left\|x_{n}-x\right\|\left\|x_{n+1}-q\right\|+\alpha_{n}\left\langle f(x)-x, j\left(x_{n+1}-q\right)\right\rangle \\
& +\beta_{n}\left\|x_{n}-x\right\|\left\|x_{n+1}-x\right\|+\gamma_{n}\left\|Q_{C} e_{n}-x\right\|\left\|x_{n+1}-x\right\| \\
\leq & \frac{\alpha_{n} \kappa+\beta_{n}}{2}\left(\left\|x_{n}-x\right\|^{2}+\left\|x_{n+1}-x\right\|^{2}\right)+\alpha_{n}\left\langle f(x)-x, j\left(x_{n+1}-x\right)\right\rangle
\end{aligned}
$$




$$
\begin{aligned}
& +\frac{\gamma_{n}}{2}\left(\left\|e_{n}-x\right\|^{2}+\left\|x_{n+1}-x\right\|^{2}\right) \\
\leq & \frac{\alpha_{n} \kappa+\beta_{n}}{2}\left\|x_{n}-x\right\|^{2}+\frac{1-\alpha_{n}(1-\kappa)}{2}\left\|x_{n+1}-x\right\|^{2} \\
& +\alpha_{n}\left\langle f(x)-x, j\left(x_{n+1}-x\right)\right\rangle+\frac{\gamma_{n}}{2}\left\|e_{n}-x\right\|^{2} .
\end{aligned}
$$

It follows that

$$
\begin{aligned}
\left\|x_{n+1}-x\right\|^{2} \leq & \left(1-\alpha_{n}(1-\kappa)\right)\left\|x_{n}-x\right\|^{2} \\
& +2 \alpha_{n}\left\langle f(x)-x, j\left(x_{n+1}-x\right)\right\rangle+\gamma_{n}\left\|e_{n}-x\right\|^{2} .
\end{aligned}
$$

Using Lemma 2.3, we find from the restrictions (a) and (b) that

$$
\lim _{n \rightarrow \infty}\left\|x_{n}-x\right\|=0
$$

This completes the proof.

Remark 3.2 The framework of the space in Theorem 3.1 can be applicable to $L^{p}, p \geq 2$.

\section{Applications}

In this section, we always assume that $E$ is a uniformly convex and 2-uniformly smooth Banach space. Let $C$ be a nonempty, closed and convex subset of $E$.

First, we consider common fixed points of two strict pseudocontractions.

Theorem 4.1 Let E be a uniformly convex and 2-uniformly smooth Banach space with the best smooth constant $K$, and let $C$ be a nonempty closed convex subset of $E$. Let $Q_{C}$ be a sunny nonexpansive retraction from $E$ onto $C$, and let $T: C \rightarrow C$ be an $\alpha$-strict pseudocontraction. Let $S: C \rightarrow C$ be a $\lambda$-strict pseudocontraction. Assume that $F:=F(S) \cap F(T) \neq \emptyset$. Let $\left\{\alpha_{n}\right\},\left\{\beta_{n}\right\}$ and $\left\{\gamma_{n}\right\}$ be real number sequences in $(0,1)$. Suppose that $x_{1}=x \in C$ and that $\left\{x_{n}\right\}$ is given by

$$
x_{n+1}=\alpha_{n} f\left(x_{n}\right)+\left(1-\alpha_{n}\right)\left[\mu S_{t} x_{n}+(1-\mu)\left((1-\alpha) x_{n}+\alpha T x_{n}\right)\right], \quad n \geq 1,
$$

where $S_{t}=(1-t) x+t S x, t \in\left(0, \frac{\lambda}{K^{2}}\right], f: C \rightarrow C$ is a $\kappa$-contractive mapping, $\left\{e_{n}\right\}$ is a bounded computational error in $E, \lambda \in\left(0, \alpha / K^{2}\right]$ and $\mu \in(0,1)$. Assume that the following restrictions are satisfied:

(a) $\lim _{n \rightarrow \infty} \alpha_{n}=0, \sum_{n=1}^{\infty} \alpha_{n}=\infty$ and $\sum_{n=1}^{\infty}\left|\alpha_{n+1}-\alpha_{n}\right|<\infty$;

(b) $\sum_{n=1}^{\infty} \gamma_{n}<\infty$.

Then $\left\{x_{n}\right\}$ converges strongly to $x=Q_{F} f(x)$, where $Q_{F}$ is a sunny nonexpansive retraction from $C$ onto $F$.

Proof Since $(I-T)$ is an $\alpha$-inverse strongly accretive mapping, we find from Theorem 3.1 the desired conclusion.

Closely related to the class of pseudocontractive mappings is the class of accretive mappings. Recall that an operator $B$ with domain $D(B)$ and range $R(B)$ in $E$ is accretive if for 
each $x_{i} \in D(B)$ and $y_{i} \in B x_{i}(i=1,2)$,

$$
\left\langle y_{2}-y_{1}, J\left(x_{2}-x_{1}\right)\right\rangle \geq 0
$$

An accretive operator $B$ is $m$-accretive if $R(I+r B)=E$ for each $r>0$. Next, we assume that $B$ is $m$-accretive and has a zero (i.e., the inclusion $0 \in B(z)$ is solvable). The set of zeros of $B$ is denoted by $\Omega$. Hence,

$$
\Omega=\{z \in D(B): 0 \in B(z)\}=B^{-1}(0) .
$$

For each $r>0$, we denote by $J_{r}$ the resolvent of $B$, i.e., $J_{r}=(I+r B)^{-1}$. Note that if $B$ is $m$-accretive, then $J_{r}: E \rightarrow E$ is nonexpansive and $F\left(J_{r}\right)=\Omega$ for all $r>0$.

From the above, we have the following theorem.

Theorem 4.2 Let E be a uniformly convex and 2-uniformly smooth Banach space with the best smooth constant $K$, and let $C$ be a nonempty, closed and convex subset of $E$. Let $Q_{C}$ be a sunny nonexpansive retraction from $E$ onto $C$, and let $A: C \rightarrow E$ be an $\alpha$-inverse strongly accretive mapping. Let $B: C \rightarrow C$ be an $m$-accretive operator. Assume that $F:=$ $A^{-1}(0) \cap B^{-1}(0) \neq \emptyset$. Let $\left\{\alpha_{n}\right\},\left\{\beta_{n}\right\}$ and $\left\{\gamma_{n}\right\}$ be real number sequences in $(0,1)$. Suppose that $x_{1}=x \in C$ and that $\left\{x_{n}\right\}$ is given by

$$
x_{n+1}=\alpha_{n} f\left(x_{n}\right)+\beta_{n}\left[\mu J_{r} x_{n}+(1-\mu)\left(x_{n}-\lambda A x_{n}\right)\right]+\gamma_{n} Q_{C} e_{n}, \quad n \geq 1 \text {, }
$$

where $J_{r}=(I+r B)^{-1}, f: C \rightarrow C$ is a $\kappa$-contractive mapping, $\left\{e_{n}\right\}$ is a bounded computational error in $E, \lambda \in\left(0, \alpha / K^{2}\right]$ and $\mu \in(0,1)$. Assume that the following restrictions are satisfied:

(a) $\lim _{n \rightarrow \infty} \alpha_{n}=0, \sum_{n=1}^{\infty} \alpha_{n}=\infty$ and $\sum_{n=1}^{\infty}\left|\alpha_{n+1}-\alpha_{n}\right|<\infty$;

(b) $\sum_{n=1}^{\infty} \gamma_{n}<\infty$.

Then $\left\{x_{n}\right\}$ converges strongly to $x=Q_{F} f(x)$, where $Q_{F}$ is a sunny nonexpansive retraction from $C$ onto $F$.

\section{Competing interests}

The authors declare that they have no competing interests.

Authors' contributions

All authors contributed equally to this manuscript. All authors read and approved the final manuscript.

\section{Author details}

'School of Mathematics and Physics, North China Electric Power University, Baoding, 071003, China. ${ }^{2}$ School of Mathematics and Sciences, Shijiazhuang University of Economics, Shijiazhuang, 050031, China.

\section{Acknowledgements}

The authors are grateful to the reviewers for useful suggestions which improved the contents of this paper.

Received: 16 March 2014 Accepted: 21 May 2014 Published: 29 May 2014

\section{References}

1. Zegeye, $\mathrm{H}$, Shahzad, N: Strong convergence theorem for a common point of solution of variational inequality and fixed point problem. Adv. Fixed Point Theory 2, 374-397 (2012)

2. Cho, SY, Kang, SM: Approximation of common solutions of variational inequalities via strict pseudocontractions. Acta Math. Sci. 32, 1607-1618 (2012)

3. Qin, X, Su, Y: Approximation of a zero point of accretive operator in Banach spaces. J. Math. Anal. Appl. 329, 415-424 (2007)

4. Qin, X, Shang, M, Su, Y: Strong convergence of a general iterative algorithm for equilibrium problems and variational inequality problems. Math. Comput. Model. 48, 1033-1046 (2008) 
5. liduka, H, Takahashi, W: Strong convergence theorems for nonexpansive mappings and inverse-strongly monotone mappings. Nonlinear Anal. 61, 341-350 (2005)

6. LV, S, Wu, C: Convergence of iterative algorithms for a generalized variational inequality and a nonexpansive mapping. Eng. Math. Lett. 1, 44-57 (2012)

7. $\mathrm{Wu}, \mathrm{C}$ : Strong convergence theorems for common solutions of variational inequality and fixed point problems. Adv. Fixed Point Theory 4, 229-244 (2014)

8. Wu, C, Liu, A: Strong convergence of a hybrid projection iterative algorithm for common solutions of operator equations and of inclusion problems. Fixed Point Theory Appl. 2012, Article ID 90 (2012)

9. Wu, C: Wiener-Hope equations methods for generalized variational inequalities. J. Nonlinear Funct. Anal. 2013, Article ID 3 (2013)

10. Qin, X, Chang, SS, Cho, YJ: Iterative methods for generalized equilibrium problems and fixed point problems with applications. Nonlinear Anal. 11, 2963-2972 (2010)

11. Bnouhachem, A: On LQP alternating direction method for solving variational inequality problems with separable structure. J. Inequal. Appl. 2014, Article ID 80 (2014)

12. Qin, X, Cho, SY, Wang, L: A regularization method for treating zero points of the sum of two monotone operators. Fixed Point Theory Appl. 2014, Article ID 75 (2014)

13. Chen, JH: Iterations for equilibrium and fixed point problems. J. Nonlinear Funct. Anal. 2013, Article ID 4 (2013)

14. Guan, WB: An iterative method for variational inequality problems. J. Inequal. Appl. 2013, Article ID 574 (2013)

15. Qin, $X, C h o, S Y$, Kang, SM: Convergence of an iterative algorithm for systems of variational inequalities and nonexpansive mappings with applications. J. Comput. Appl. Math. 233, 231-240 (2009)

16. He, R: Coincidence theorem and existence theorems of solutions for a system of Ky Fan type minimax inequalities in FC-spaces. Adv. Fixed Point Theory 2, 47-57 (2012)

17. Cho, SY, Qin, X: On the strong convergence of an iterative process for asymptotically strict pseudocontractions and equilibrium problems. Appl. Math. Comput. 235, 430-438 (2014)

18. Luo, H, Wang, Y: Iterative approximation for the common solutions of an infinite variational inequality system for inverse-strongly accretive mappings. J. Math. Comput. Sci. 2, 1660-1670 (2012)

19. Wang, ZM, Lou, W: A new iterative algorithm of common solutions to quasi-variational inclusion and fixed point problems. J. Math. Comput. Sci. 3, 57-72 (2013)

20. LV, S: Strong convergence of a general iterative algorithm in Hilbert spaces. J. Inequal. Appl. 2013, Article ID 19 (2013)

21. Cho, SY, Qin, $X$, Wang, L: Strong convergence of a splitting algorithm for treating monotone operators. Fixed Point Theory Appl. 2014, Article ID 94 (2014)

22. Hao, Y: On variational inclusion and common fixed point problems in Hilbert spaces with applications. Appl. Math. Comput. 217, 3000-3010 (2010)

23. Kim, KS, Kim, JK, Lim, WH: Convergence theorems for common solutions of various problems with nonlinear mapping. J. Inequal. Appl. 2014, Article ID 2 (2014)

24. Wang, G, Sun, S: Hybrid projection algorithms for fixed point and equilibrium problems in a Banach space. Adv. Fixed Point Theory 3, 578-594 (2013)

25. Cho, SY, Li, W, Kang, SM: Convergence analysis of an iterative algorithm for monotone operators. J. Inequal. Appl. 2013, Article ID 199 (2013)

26. Hao, Y: Strong convergence of an iterative method for inverse strongly accretive operators. J. Inequal. Appl. 2008 Article ID 420989 (2008)

27. Reich, S: Asymptotic behavior of contractions in Banach spaces. J. Math. Anal. Appl. 44, $57-70$ (1973)

28. Kitahara, S, Takahashi, W: Image recovery by convex combinations of sunny nonexpansive retractions. Topol. Methods Nonlinear Anal. 2, 333-342 (1993)

29. Aoyama, K, liduka, $\mathrm{H}$, Takahashi, W: Weak convergence of an iterative sequence for accretive operators in Banach spaces. Fixed Point Theory Appl. 2006, Article ID 35390 (2006)

30. Liu, LS: Ishikawa and Mann iteration process with errors for nonlinear strongly accretive mappings in Banach spaces. J. Math. Anal. Appl. 194, 114-125 (1995)

31. Xu, HK: Inequalities in Banach spaces with applications. Nonlinear Anal. 16, 1127-1138 (1991)

32. Bruck, RE: Properties of fixed point sets of nonexpansive mappings in Banach spaces. Trans. Am. Math. Soc. 179, 251-262 (1973)

33. Zhou, $\mathrm{H}$ : Convergence theorems for $\lambda$-strict pseudo-contractions in 2-uniformly smooth Banach spaces. Nonlinear Anal. 69, 3160-3173 (2008)

34. Qin, $X, C h o, ~ S Y$, Wang, L: Iterative algorithms with errors for zero points of $m$-accretive operators. Fixed Point Theory Appl. 2013, Article ID 148 (2013)

10.1186/1029-242X-2014-215

Cite this article as: Yu and Song: Strong convergence theorems for solutions of fixed point and variational inequality problems. Journal of Inequalities and Applications 2014, 2014:215 